Информация об авторах

Неверов Евгений Николаевич, заведующий кафедрой техносферной безопасности ФГБОУ ВО «Кемеровский государственный университет» (РФ, 650043, г. Кемерово, ул. Красная, 6), доктор технических наук, тел. 89235215385, e-mail: neverov42@mail.ru

Короткий Игорь Алексеевич, заведующий кафедрой теплохладотехники ФГБОУ ВО «Кемеровский государственный университет» (РФ, 650043, г. Кемерово, ул. Красная, 6), доктор технических наук, тел. 7 (3842) 39-68-70, e-mail: krot69@mail.ru

Коротких Павел Сергеевич, ассистент кафедры теплохладотехники ФГБОУ ВО «Кемеровский государственный университет» (РФ, 650043, г. Кемерово, ул. Красная, 6), тел. 89059124022, e-mail: korotkix42@gmail.com

Неверова Ольга Александровна, директор института «Биологии, экологии и природных ресурсов» ФГБОУ ВО «Кемеровский государственный университет» (РФ, 650043, г. Кемерово, ул. Красная, 6), доктор технических наук, тел. 8923600-73-67, e-mail: nev11@yandex.ru

Проскурякова Лариса Александровна, профессор кафедры «Психология и общая педагогика» ФГБОУ ВО «Кемеровский государственный университет», (РФ, 650043, г. Кемерово, ул. Красная, 6), доктор технических наук, тел. 8913079-90-42 e-mail: lora-al@.yandex.ru

\title{
DOI: 10.32786/2071-9485-2021-03-35 SELECTION PROCEDURE FOR SUNFLOWER CLEANERS ON GRAIN CLEANING MACHINES
}

\author{
D. A. Nekhoroschev, D. D. Nekhoroschev, \\ I.V Kuznetsov, N. D. Nekhoroschev \\ Volgograd State Agrarian University, Volgograd, Russia
}

Received 29.04.2021

Submitted 20.08.2021

Summary

Harvesting of grain and industrial crops is carried out by combine harvesters equipped with threshing devices of beater and rotary type, which grind the grain mass, consisting of straw and ears. At the same time, a heap of grain threshed by a combine harvester includes grains of the main crop, as well as weed seeds and grain impurities, which affect the processing process, preparing grain for storage and obtaining seeds. Grain admixture contains damaged, broken, sprouted, shriveled, crushed, pesteaten and unripe grains. The weed admixture is subdivided into mineral (lumps of soil and sand) and organic (ears, chaff, leaves, stems). Along with the above, it is necessary to highlight the harmful admixture, which is in the heap, dangerous to human and domestic animal health (seeds of poisonous plants). The presence of weeds in the grain heap is controlled by the standard. Grain that does not meet the standards cannot be used for food purposes and for harvesting seeds without preliminary cleaning. Sometimes the primary cleaning of the grain heap is also required in the case when the presence of trash impurities is less than established by the standard. The beginning of cleaning the threshed grain heap begins even in the process of harvesting on the screen of a combine harvester. Therefore, in fields not clogged with weeds, the correct technological adjustment of the threshing apparatus allows you to eliminate the presence of crushed and crushed grains, and the adjustment of the air flow of the fan will allow you to separate light organic impurities (chaff, awn, leaves). When harvesting fields clogged with weeds, it is not always possible to remove impurities and obtain grain of good quality; in such cases, grain cleaning machines are used to obtain grain of the appropriate standards.

Keywords: grain weight, a pile of grain, graincleaning machines, sieves, coefficient of friction, grating mill.

Citation. Nekhoroschev D.A., Nekhoroschev D.D., Kuznetsov I.V., Nekhoroschev N.D. Selection procedure for sunflower cleaners on grain cleaning machines. Proc. of the Lower Volga AgroUniversity Comp. 2021. 3 (63) 337-343 (in Russian). DOI: 10.32786/2071-9485-2021-03-35.

Auhor's contribution. All authors of this research paper have directly participated in the planning, execution, or analysis of this study. All authors of tfis paper have read and approved the final version submitted.

Conflict of interest. The author declares no conflict of interest. 


\title{
***** ИЗВЕСТИЯ ***** \\ НИЖНЕВОАЖСКОГО АГРОУНИВЕРСИТЕТСКОГО КОМПАЕКСА \\ НАУКА И ВЫСШЕЕ ПРОФЕССИОНААЬНОЕ ОБРАЗОВАНИЕ \\ УДК 631.362.221 \\ МЕТОДИКА ВЫБОРА РЕШЁТ ДЛЯ ОЧИСТКИ ПОДСОЛНЕЧНИКА НА ЗЕРНООЧИСТИТЕЛЬНЫХ МАШИНАХ
}

№ 3 (63), 2021

\author{
Д. А. Нехорошев, доктор технических наук, профессор \\ Д. Д. Нехорошев, кандидат технических наук, дочент \\ И. В. Кузнецов, аспирант \\ Н. Д. Нехорошев, студент
}

Волгоградский государственный аграрный университет, г.Волгоград

Дата поступления в редакцию 29. 04.2021

Дата принятия к печати 20.08.2021

Уборка зерновых и технических культур проводится зерноуборочными комбайнами, оснащенными молотильными аппаратами бильного и роторного типа, которые перетирают хлебную массу, состоящую из соломы и колосьев. При этом обмолоченный комбайном ворох зерна включает зёрна основной культуры, а также семена сорных растений и зерновую примесь, которые влияют на процесс переработки, подготовки зерна к хранению и получению семян. Зерновая примесь содержит поврежденные, битые, проросшие, щуплые, давленые, поеденные вредителями и недозрелые зерна. Сорная примесь подразделяется на минеральную (комочки почвы и песок) и органическую (колосья, полова, листья, стебли). Наряду с вышеперечисленными, следует выделить и вредную, находящуюся в ворохе, опасную для здоровья человека и домашних животных примесь (семена ядовитых растений). Наличие сорных примесей в зерновом ворохе контролируется стандартом. Зерно, не соответствующее стандартам, нельзя использовать в продовольственных целях и для заготовки семян без предварительной очистки. Иногда первичная очистка зернового вороха требуется и в том случае, когда количество сорных примесей меньше установленных стандартом. Начало очистки обмолоченного зернового вороха начинается ещё в процессе уборки на грохоте зерноуборочного комбайна. Поэтому на полях, не засорённых сорняками, правильная технологическая регулировка молотильного аппарата позволяет устранить наличие колотых и дроблёных зёрен, а регулировка воздушного потока вентилятора позволит отделить легкие органические примеси (полову, ости, листья). При уборке полей, засорённых сорняками, не всегда имеется возможность удалить примеси и получить зерно хорошего качества, в таких случаях используются зерноочистительные машины, позволяющие получить зерно, соответствующее стандартам.

Ключевые слова: зерновая масса, ворох зерна, зерноочистительные машины, решёта, коэффициент трения, решётный стан.

Цитирование. Нехорошев Д. А., Нехорошев Д. Д., Кузнецов И. В., Нехорошев Н. Д. Методика выбора решёт для очистки подсолнечника на зерноочистительных машинах. Известия НВ АУК. 2021. 3(63). 337-343. DOI: 10.32786/2071-9485-2021-03-35.

Авторский вклад. Все авторы настоящего исследования принимали непосредственное участие в планировании, выполнении или анализе данного исследования. Все авторы настоящей статьи ознакомились и одобрили представленный окончательный вариант.

Конфликт интересов. Авторы заявляют об отсутствии конфликта интересов.

Введение. Хранение продовольственного зерна, подготовка к реализации и получение качественного семенного материала во многом зависит от технологического процесса очистки зерна и конструкции зерноочистительных машин. Для этих целей выбираются машины, в устройстве которых используется одновременно несколько режимов очистки: аспирационная, решётная и разделение на ячеистых поверхностях. Наибольшее распространение получили зерноочистительные машины с воздушно-решётным способом сепарации. В конструкции этих машин используются плоские пробивные решёта, они монтируются в решётном стане, который приводится в движение коленчатым валом или эксцен- 
триковым механизмом, совершая возвратно поступательные движения. Разделение зерновой массы на решётах производится по геометрическим параметрам: на решётах с прямоугольными отверстиями по толщине, а на решётах с круглыми отверстиями - по ширине $[1,6,8]$. При этом качество технологического процесса очистки зернового вороха зависит от удельной производительности площади поверхности сепарации решётного стана и запланированного качества выполняемых работ [3, 4].

Материалы и методы. В конструкциях современных зерноочистительных машин используют одновременно несколько способов разделения зерна $[9,13]$. Следует отметить, что большинство зерноочистительных машин для первичной очистки зерна и подготовки семенного материала используют решётный способ очистки, который позволяет реализовать качественную сортировку за счёт разделения зернового вороха по геометрическим параметрам $[2,10,12]$. Существующие зерноочистительные машины имеют небольшие конструктивные отличия, но технологический процесс движения зерна по решётам, представленный на рисунке 1, для них аналогичен.

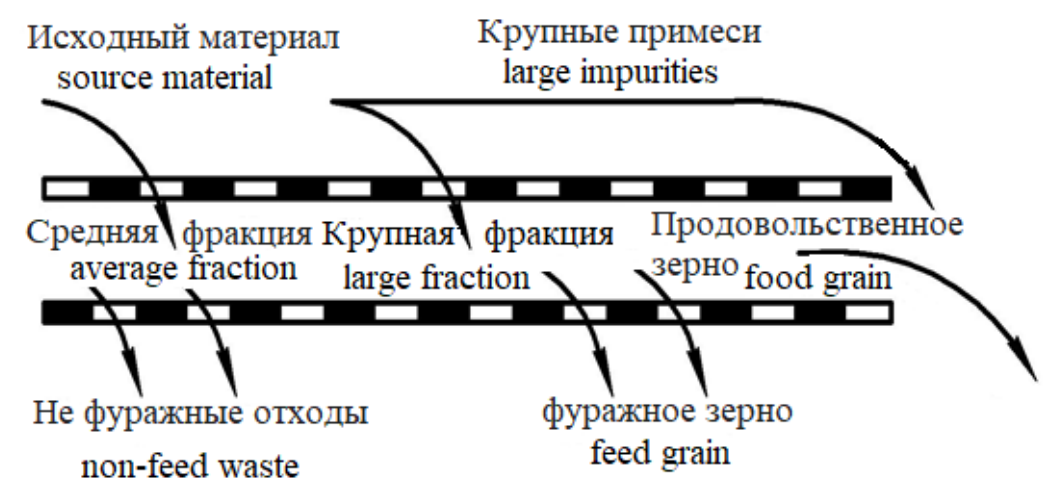

Рисунок 1 - Технологический процесс движения зерна на решётах

Figure 1 - Technological process of grain movement on sieves

Поступающий на очистку зерновой ворох подлежит разделению на следующие фракции: крупные примеси; нефуражные отходы (подсев); колотое, щуплое и мелкое зерно (фуражные отходы); продовольственное сортированное зерно (первый сорт). Для того чтобы получить качественное разделение вороха на соответствующие фракции, необходимо при очистке подбирать решёта соответствующие перерабатываемой культуре (таблица 1).

Таблица 1 - Предварительные размеры решёт для очистки зерновых и технических культур

Table 1 - Preliminary sizes of sieves for cleaning grain and industrial crops

\begin{tabular}{|c|c|c|c|}
\hline Культура / Culture & $\begin{array}{c}\text { Отделение крупных } \\
\text { примесей (сход), мм / } \\
\text { Separation of large im- } \\
\text { purities (convergence), } \\
\text { mm }\end{array}$ & $\begin{array}{l}\text { Отделение мелких } \\
\text { примесей (подсев), } \\
\text { мм / Separation of } \\
\text { small impurities } \\
\text { (seeding), mm }\end{array}$ & $\begin{array}{c}\text { Отделение фу- } \\
\text { ражного зерна } \\
\text { (отходы), мм / } \\
\text { Feed grain separa- } \\
\text { tion (waste), mm }\end{array}$ \\
\hline Пшеница / Wheat & $\begin{array}{l}\varnothing 4,0-7,0 \\
\square 3,0-4,0\end{array}$ & $\begin{array}{l}\varnothing 2,0-2,5 \\
\square 1,7-2,2\end{array}$ & $\begin{array}{l}\varnothing 2,5-3,0 \\
\square 2,0-2,4\end{array}$ \\
\hline Ячмень / Barley & $\begin{array}{l}\varnothing 5,0-8,0 \\
\square 2,6-3,6\end{array}$ & $\begin{array}{c}\varnothing 2,5 \\
\square 2,0-2,4\end{array}$ & $\begin{array}{c}\varnothing 3,0 \\
\square 2,2-2,6\end{array}$ \\
\hline $\begin{array}{l}\text { Подсолнечник / } \\
\text { Sunflower }\end{array}$ & $\begin{array}{c}\varnothing 9,0-12,0 \\
\square 4,5-5,0\end{array}$ & $\begin{array}{c}\varnothing 3,6-4,0 \\
-\end{array}$ & $\begin{array}{c}- \\
\square 2,0-3,0\end{array}$ \\
\hline
\end{tabular}

Обозначения: $\varnothing$ - решето с круглыми отверстиями; $\square-$ решето с прямоугольными отверстиями. 
Результаты и обсуждение. Подбор решёт и размеров сепарирующих отверстий производится с использованием вариационных кривых распределения геометрических параметров основной культуры и примесей, характеристиками которых являются средний размер семян т и среднее квадратическое отклонение $\sigma$, геометрических параметров семян от среднего значения [5]. При достаточно большом числе выполненныХ нами замеров распределение семян можно описать кривой распределения Гаусса (рисунок 2).

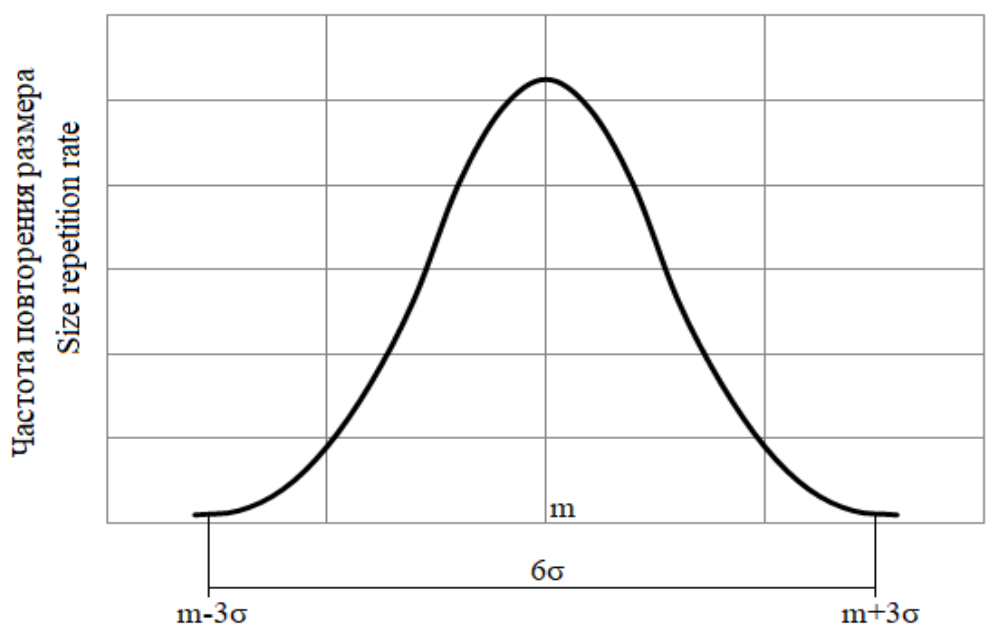

Рисунок 2 - Кривая Гаусса для распределения размеров семян

Figure 2 - The Gaussian curve for the distribution of seed sizes

Используя закон нормального распределения, определим геометрические параметры зерна подсолнечника:

$$
f(l)=\frac{1}{\sigma \sqrt{2} \pi} e^{-\frac{U^{2}}{2}},
$$

где $\sigma$ - среднеквадратическое отклонение длины зерна подсолнечника $l ; U=(l-m) / \sigma$ - отклонение длины зерна подсолнечника $l$ от математического ожидания.

Тогда, чтобы определить вариационные кривые распределения длины зерна подсолнечника, используем математическую функцию $\varphi(\mathrm{U})$, которая представлена формулой (2):

$$
\varphi(U)=f(l) \cdot \sigma=\frac{1}{\sqrt{2 \pi}} e^{-\frac{U^{2}}{2}}
$$

Чтобы построить вариационные кривые, необходимо определить минимальные $l_{\min }$ и максимальные $l_{\max }$ значения длины семян:

$$
\begin{gathered}
l_{\text {min }}=m-3 \sigma ; \\
l_{\text {max }}=m+3 \sigma .
\end{gathered}
$$

На графике кривой распределения размеров семян по оси х (рисунок 2) обозначают значения длины семян $l_{\min }, l_{\max }$ и $m$. Полученные значения от $m$ до $l_{\min }$ и $m$ до $l_{\max }$ делим на 4 равные части. Им соответствуют точки: $0 ; 0,75 \cdot \sigma ; 1,5 \cdot \sigma ; 2,25 \cdot \sigma ; 3,00 \cdot \sigma$, которые отражают величину математического ожидания.

Используя в расчётах формулу (2), получаем:

$$
f(l)=\frac{\varphi(U)}{\sigma} .
$$


Полученные данные теоретических расчётов позволяют проводить корректировку размеров решёт при подготовке зерноочистительных машин к работе. Учитывая качество очистки зернового материала необходимо соблюдать следующие требования подбора решёт. Размер сепарирующих отверстий решёт для выделения крупных примесей определяется выражением $\mathrm{m}+3 \sigma$, для выделения мелких примесей (не фуражные отходы) $\mathrm{m}-3 \sigma$, для выделения мелких и щуплых семян (фуражные отходы) $\mathrm{m}-\sigma$.

На первом этапе подбора решёт определяют вид очистки: первичная очистка, сортировка или калибровка. В соответствии с видами очистки выбирают тип решёт и последовательность расположения их в решетном стане (таблица 3). С целью повышения эффективности очистки первыми, устанавливают решёта с прямоугольными отверстиями, которые разделяют ворох по толщине (Т). Для отделения крупных примесей устанавливают решёта с круглыми отверстиями, которые разделяют ворох по ширине (Ш). Выход не фуражных отходов (подсев) происходит на решётах с круглыми отверстиями. Для отделения фуражного зерна устанавливаются решета с прямоугольными отверстиями. Получение калиброванного семенного зерна требует использования триерных барабанов, которые разделяют ворох по длине (Д).

Таблица 3 - Данные по распределению геометрических размеров семян подсолнечника

Table 3 - Data on the distribution of geometric dimensions 'of sunflower seeds

\begin{tabular}{|c|c|c|c|c|c|c|c|c|c|c|c|}
\hline $\begin{array}{l}\text { Культура / } \\
\text { Culture }\end{array}$ & & $\begin{array}{l}\text { ззмеры } \\
\text { ян / Seed } \\
\text { sizes }\end{array}$ & $\begin{array}{l}0 \\
\dot{0} \\
\dot{1}\end{array}$ & 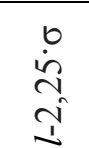 & $\stackrel{0}{i}$ & $\begin{array}{l}0 \\
\dot{n} \\
i \\
i \\
i\end{array}$ & $\stackrel{0}{-}$ & $\begin{array}{c}\stackrel{b}{r} \\
\stackrel{0}{0} \\
\dot{1}\end{array}$ & $\stackrel{0}{\dot{n}}$ & $\begin{array}{l}\stackrel{b}{i n} \\
\stackrel{i}{1} \\
\stackrel{ \pm}{ \pm}\end{array}$ & $\begin{array}{l}\dot{0} \\
\dot{0} \\
\dot{ \pm}\end{array}$ \\
\hline \multirow{6}{*}{$\begin{array}{l}\text { Подсолнеч- } \\
\text { ник / } \\
\text { Sunflower }\end{array}$} & \multirow[t]{2}{*}{$\mathrm{T}$} & $\begin{array}{l}\text { Раз- } \\
\text { мер,мм/ } \\
\text { Size, } \\
\text { mm }\end{array}$ & 1,56 & 1,71 & 2,03 & 2,12 & 2,3 & 2.50 & 2.68 & 2.87 & 3.20 \\
\hline & & $f(l)$ & 0,01 & 0,16 & 0,51 & 1,2 & 1,5 & 1,2 & 0,51 & 0,12 & 0,01 \\
\hline & \multirow[t]{2}{*}{ Ш } & $\begin{array}{l}\text { Раз- } \\
\text { мер,мм/ } \\
\text { Size, } \\
\text { mm }\end{array}$ & 1,81 & 1,99 & 2,01 & 2,40 & 2,6 & 2,78 & 3,01 & 3,30 & 3,50 \\
\hline & & $f(l)$ & 0,02 & 0,12 & 0,47 & 1,13 & 1,3 & 1,14 & 0,47 & 0,16 & 0,01 \\
\hline & \multirow[t]{2}{*}{ Д } & $\begin{array}{l}\text { Paз- } \\
\text { мер,мm/ } \\
\text { Size, } \\
\text { mm }\end{array}$ & 4,97 & 6,0 & 6,19 & 6,7 & 7,8 & 8,0 & 8,63 & 9,1 & 9,8 \\
\hline & & $f(l)$ & 0,01 & 0,04 & 0,18 & 0,42 & 0,5 & 0,42 & 0,18 & 0,04 & 0,01 \\
\hline
\end{tabular}

Качество и эффективность работы зерноочистительной машины при очистке семян подсолнечника зависит от технической характеристики выбранной машины. При выборе машины необходимо учитывать: коэффициент трения зерна по решётам; угол наклона, частоту и амплитуду колебаний решетного стана; скорость воздушного потока аспирационной системы; процент засорённости очищаемого зерна [7, 11].

Выводы. На основе анализа основных операций технологического процесса очистки и сортировки семян зерновых и подсолнечника на зерноочистительных машинах, использующих для разделения зерновой массы решёта с круглыми и с прямоугольными отверстиями, были определены основные параметры размеров отверстий. 
Следует отметить, что для получения качественного семенного материала при очистке подсолнечника необходимо величину воздушного потока в аспирационных каналах первой и второй ступени уменьшить до 4,3 ...5,3 м/с. Решёта установить в следующей последовательности: верхние с прямоугольными отверстиями - $\square$ 4,2..5,6 мм, с круглыми отверстиями - Ø 8,2...10,2 мм; нижние с круглыми - Ø 2,4...3,6 мм, с прямоугольными - $\square 2,2 \ldots 2,6$ мм.

\section{Библиографический список}

1. Анискин В. И. Развитие зерноочистительной техники // Тракторы и сельскохозяйственные машины. 2005. № 1. С. 12-14.

2. Гиевский А. М. Обоснование схемы размещения и соотношения решет в решетных станах // Лесотехнический журнал. 2013. № 3. С. 36-46.

3. Гиевский А. М. Повышение эффективности работы двухаспирационной пневмосистемы универсальной воздушно-решетной зерноочистительной машины // Тракторы и сельхозмашины. 2014. № 5. С. 32-34.

4. Ермольев Ю. И. Модельное прогнозирование показателей функционирования воздушнорешётной зерноочистительной машины от роста эффективности операции пневмосепарации // Вестник Донского государственного технического университета. 2014. Т. 14. № 1 (76). С. 122-134.

5. Жолобов Н. В. Решётные сепараторы зерноочистительных машин. Киров: Вятская ГСХА, 2005. $47 \mathrm{c}$.

6. Казаров К. Р. Технологии и средства механизации сушки и послеуборочной обработки зерна. Воронеж: ФГБОУ ВО Воронежский ГАУ, 2016. 310 с.

7. Тарасенко А. П. Качественные показатели работы машин для вторичной очистки зерна // Сельскохозяйственные машины и технологии. 2011. № 3. С. 36-39.

8. Тарасенко А. П. Фракционирование зернового вороха на решетах // Сельскохозяйственные машины и технологии. 2012. № 5. С. 26-29.

9. Evaluation of reliability of sorghum harvester / A. S. Ovchinnikov [et al.] // ARPN Journal of Engineering and Applied Sciences. 2017. V. 12 (7). P. 2277-2284. www.scopus.com

10. Krach W. Techik der Siebung in der Getreidemullerei // Mehlund Brot. 1977. Vol. 31-2. P. 43-48.

11. Physical Properties of Agricultural Materials and their influence on Design and Performance of Agricultural Machines and Technologies // Collection of papers Facultu of Mechanization, College of Agricultural in Parague Vysoka skela zemedelska. Prage, 1985. 202 p.

12. Stanger E. A. Graing - cleaning machinery // Milling fced and fertiliser. 1977. Vol. 160. № 8. P. 11-15.

13. Wessel J. Verfahren des Siebens und des Windsichtens // Grundlagen des Landtechn. Bd. 18. 1968. № 4. P. 151-157.

Conclusions. Based on the analysis of the main operations of the technological process of cleaning and sorting grain and sunflower seeds on grain cleaning machines using sieves with round and straight-angle holes for separating the grain mass, the main parameters of the hole sizes were determined. It should be noted that in order to obtain high-quality seed material during sunflower cleaning, it is necessary to reduce the air flow in the aspiration channels of the first and second stages to $4.3 \ldots . .3 \mathrm{~m} / \mathrm{s}$. The sieves should be installed in the following sequence: the upper ones with rectangular holes - 4.2...5.6 mm, with round holes - 8.2..10.2 mm; the lower ones with round holes $-2.4 \ldots 3.6 \mathrm{~mm}$, with rectangular ones $-2.2 \ldots .2 .6 \mathrm{~mm}$.

\section{Reference}

1. Aniskin V. I. Development of grain cleaning equipment // Tractors and agricultural machines. 2005. № 1. P. 12-14.

2. Gievsky A. M. Substantiation of the layout scheme and the ratio of sieves in sieve mills // Lesotechnical journal. 2013. № 3. P. 36-46. 
3. Gievsky A. M. Improving the efficiency of the two-air pneumatic system of the universal air-sieve grain cleaning machine // Tractors and agricultural machines. 2014. № 5. P. 32-34 .

4. Ermolyev Yu. I. Model forecasting of the functioning indicators of an air-sieve grain cleaning machine from the increase in the efficiency of the pneumatic separation operation // Bulletin of the Don State Technical University. 2014. V. 14. № 1 (76). P. 122-134.

5. Zholobov N. V. Sieve separators of grain cleaning machines. Kirov: Vyatka State Agricultural Academy, 2005. $47 \mathrm{p}$.

6. Kazarov K. R. Technologies and means of mechanization of drying and post-harvest processing of grain. Voronezh: Voronezh State Agrarian University, 2016. 310 p.

7. Tarasenko A. P. Qualitative performance indicators of machines for secondary grain cleaning // Agricultural machines and technologies. 2011. № 3. P. 36-39.

8. Tarasenko A. P. Fractionation of a grain heap on sieves // Agricultural machines and technologies. 2012. № 5. P. 26-29.

9. Evaluation of reliability of sorghum harvester / A. S. Ovchinnikov [et al.] // ARPN Journal of Engineering and Applied Sciences. 2017. V. 12 (7). P. 2277-2284. www.scopus.com

10. Krach W. Techik der Siebung in der Getreidemullerei // Mehlund Brot. 1977. Vol. 312. P. 43-48.

11. Physical Properties of Agricultural Materials and their influence on Design and Performance of Agricultural Machines and Technologies // Collection of papers Facultu of Mechanization, College of Agricultural in Parague Vysoka skela zemedelska. Prage, 1985. 202 p.

12. Stanger E. A. Graing - cleaning machinery // Milling fced and fertiliser. 1977. Vol. 160. № 8. P. 11-15.

13. Wessel J. Verfahren des Siebens und des Windsichtens // Grundlagen des Landtechn. Bd. 18. 1968. № 4. P. 151-157.

\section{Authors Information}

Dmitry Dmitrievich Nekhoroshev, Associate Professor of the Department «Energy Systems and Power Plants». Volgograd State Agrarian University (26, Universitetskiy Ave., Volgograd, 400002, Russian Federation), Candidate of Technical Sciences, Associate Professor.ndd. volgau.@yandecx.ru

Dmitry Artemovich Nekhoroshev, Professor of the Department of «Technical Systems in the agroindustrial complex». Volgograd State Agrarian University (26, Universitetskiy Ave., Volgograd, 400002, Russian Federation), Doctor of Technical Sciences, Associate Professor, ORCID: https://orcid.org/00000001-5064-2974_dmitr-nech@yandecx.ru

Kuznetsov Ivan Vladimirovich, post-graduate student of the department «Technical systems in agriculture». Volgograd State Agrarian University (26, Universitetskiy Ave., Volgograd, 400002, Russian Federation), laser94@mail.ru

Nikita Dmitrievich Nekhoroshev, a student of the «Faculty of Engineering and Technology». Volgograd State Agrarian University (26, Universitetskiy Ave., Volgograd, 400002, Russian Federation), nikita.nech@yandex.ru

\section{Информация об авторах}

Нехорошев Дмитрий Артёмович, профессор кафедры «Технические системы в АПК» Волгоградского государственного аграрного университета (РФ, 400002, г. Волгоград, пр-т, Университетский, д. 26.), доктор технических наук, доцент, ORCID: https://orcid.org/0000-0001-5064-2974 dmitrnech@yandecx.ru

Нехорошев Дмитрий Дмитриевич, доцент кафедры «Энергетические системы и электростанции» Волгоградского государственного аграрного университета (РФ, 400002, г. Волгоград, пр-т, Университетский, д. 26.), кандидат технических наук, доцент. ndd. volgau.@yandecx.ru

Кузнецов Иван Владимирович, аспирант кафедры «Технические системы в АПК» Волгоградского государственного аграрного университета (РФ, 400002, г. Волгоград, пр-т, Университетский, д. 26.), laser94@mail.ru

Нехорошев Никита Дмитриевич, студент «Инженерно-технологического факультета» Волгоградского государственного аграрного университета (РФ, 400002, г. Волгоград, пр-т, Университетский, д. 26.), nikita.nech@yandex.ru 